\title{
ADROIT Electronically Generated Information Service
}

National Cancer Institute

\section{Source}

National Cancer Institute. ADROIT Electronically Generated Information Service. NCI

Thesaurus. Code C156645.

An online subscription service that provides access to anonymized adverse drug reaction data on the ADROIT database. 